\title{
Evaluation of oasis stability in the lower reaches of the Tarim River
}

\author{
Chao LENG ${ }^{1,2}$, YaNing CHEN ${ }^{1 \star}$, XinGong $\mathrm{LI}^{3}$, YanXia SUN $N^{1,2}$ \\ ${ }^{1}$ Key Laboratory of Oasis Ecology and Desert Environment, Xinjiang Institute of Ecology and Geography, Chinese Academy of \\ Sciences, Urumqi 830011, China; \\ ${ }^{2}$ Graduate University of Chinese Academy of Sciences, Beijing 100049, China; \\ ${ }^{3}$ Department of Geography, University of Kansas Lawrence, KS 66045, USA
}

\begin{abstract}
Oasis stability in the lower reaches of the Tarim River was assessed at the landscape scale (including changes in landscape pattern and land use in the oasis) and at the regional scale (including the cold-island effect and NDVI of the oasis) based on the methods of landscape ecology, GIS and Remote Sensing (RS). Thematic Mapping (TM) remote sensing images from 1990, 2000 and 2009 were employed along with the related meteorological and hydrological data pertaining to the reclamation area of the oasis in the lower reaches of the Tarim River. The results indicated that landscape heterogeneity and oasis complexity increased between 1990 and 2000. The comprehensive index of the degree of land use, the average index of the cold-island effect, NDVI value and oasis stability all decreased. However, the change trends in the indices referred to above were opposite between 2000 and 2009, and oasis stability was enhanced to some extent.
\end{abstract}

Keywords: oasis stability; landscape scale; regional scale; the lower reaches of the Tarim River

\section{Introduction}

The broad desert system, the mountain system with obvious vertical differentiation, and the oasis system which human lives depend on together make up the particular ecological landscape of the arid land in West China (Luo et al., 2003). As the most important landscape in arid land, the oasis is the main space for producing and living, and its stability is closely related to human survival and sustainable development (Wang et al., 1999; Liu et al., 2001; Chen, 2010). The study of oases has become a hot topic for research in arid areas. The stability of oases has been analyzed from oasis formation and succession (Wang et al., 1999; Song et al., 2003), from the interaction between desert and oasis (Luo et al., 2002) as well as from the aspect of landscape ecology (Jiao et al., 2003; Ma et al., 2003; Wu et al., 2009). Oasis stability has been assessed from the aspects of carrying capacity and mode of water resource allocation (Wang et al., 2002; Zhao et al., 2006). Summarizing previous work, we found little research on the stability of oases in the Tarim River basin.
The Tarim River, the longest inland river in China, has rich natural resources. However, its ecosystem is frail. The management, exploitation and utilization of water resources from the Tarim River has long been managed by different regional authorities, which has resulted in a series of problems. Allocation of water resources is illogical; there is imbalance between available water and land exploitation; there is zero flow in the downstream channel; there is a large drop in groundwater level down the basin, and natural vegetation has declined, along with the development of desertification and the intense atrophic state of the 'green corridor' between the Taklimakan and Kuruk deserts. As the ecological environment in the lower reaches of Tarim River worsens due to extreme shortage of water, the stability and sustainable development of the oases in the lower reaches become key issues that need to be addressed urgently and scientifically. From the view of system theory, the stability of oasissystems means that the systems neither change over time nor are effected by tiny swings and stochastic

\footnotetext{
Received 2010-10-22; accepted 2011-01-26

doi: $10.3724 /$ SP.J.1227.2011.00123

* Corresponding author: YaNing CHEN (E-mail: chenyn@ms.xjb.ac.cn)
} 
disturbances. Landscape ecology summarizes the stability of oases as the invariability of sustainability of landscape functions slight variability at some level. At the regional scale, oasis stability can be described as follows: The state of an oasis is considered to be steady when increased stability over time and efficient use of water is assured, when primary productivity per unit area is increasing all the time, and when the productivity of natural vegetation shows no obvious drop (Luo, 2004). Han (1999) points out that the stability of an oasis can ensure a good cycling of energy, material and information in the oasis ecosystem, can improve the survival environment for life-forms in the oasis, and can promote the sustainable and stable development of the functions of the oasis system. From the above definitions we can see that the essential meaning of oasis stability is the sustainable development of the oasis system.

The stability of oases is different at different spatio-temporal scales. The temporal and spatial variations within oases are intuitively represented by LUCC (Land Use/Cover Change) and landscape variation. In this paper, the change in oasis stability before and after ecological water transfers was analyzed at the landscape and regional scales on the basis of the foregoing definitions of oasis stability. The results revealed that ecological water transfer in the lower reaches of the Tarim River is necessary. This paper aims to supply scientific evidence for the need for ecological restoration in the lower reaches of the Tarim River.

\section{Study area}

The Tarim River is located in the northwest arid area of China. With a length of $1,321 \mathrm{~km}$, it is the longest inland river in China. The lower reaches of the Tarim River $\left(40^{\circ} 22^{\prime} 17^{\prime \prime}-40^{\circ} 57^{\prime} 18^{\prime \prime} \mathrm{N}, 86^{\circ} 41^{\prime} 48^{\prime \prime}-88^{\circ} 11^{\prime} 54^{\prime \prime} \mathrm{E}\right)$ is the area downstream from Qiala hydrologic station. The terrain of this area falls from the north-west towards the south-east over an altitude range of 811-854 $\mathrm{m}$. The vegetation type in this area is simple. Populus euphratica is the main natural tree, with representatives of shrubs of Tamarix and Halostachys. The main grasses and herbs are Apocynum, Phragmites, Glycyrrhiza and Alhagisparsifolia, etc.

The area of development (land-reclamation-cultivation) within the oasis landscape from the Qiala hydrologic station to the Daxihaizi Reservoir along the upper-midstream section of the lower reaches of the Tarim River was chosen as the study area (Zhou et al., 2010). It includes the areas administered and managed by five different corps (the $31^{\text {th }}$ corps to $35^{\text {th }}$ corps). The total study area is $25.87 \mathrm{~km}^{2}$, and the total population is 42,600 (Fig. 1). This area is an important production area for cotton and fruits.

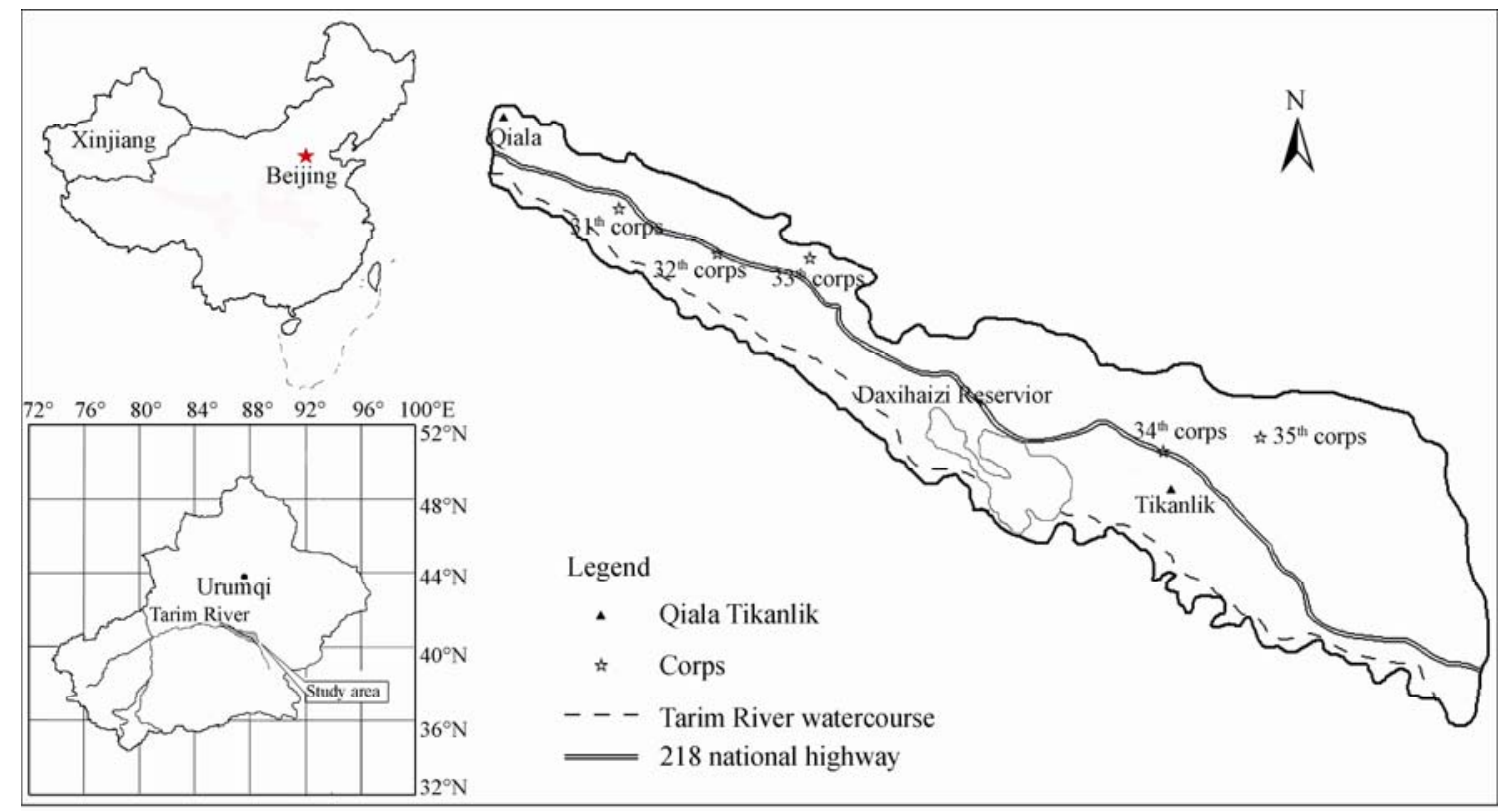

Fig. 1 Sketch of the study area 


\section{Materials and methods}

\subsection{Data sources}

Chen (2003) pointed out that the vegetation restoration in the lower reaches of the Tarim River resulted from the ecological water transfer in this area since 2000. Comparative analysis between the varieties of oasis stability before and after the ecological water transfer was carried out by extending forward and backwards 10 years from 2000 respectively. The remote sensing data from USGS Global Visualization Viewer (http://glovis.usgs.gov/) was employed. The three TM remote sensing images employed in the study were collected on Oct. 9, 1990, Aug. 9, 2000 and Aug. 10, 2009. These images are of good quality and free from cloud. We utilized the data of annual runoff and river flow in the last 50 years from Qiala hydrologic station, and the data of air temperature, precipitation and evaporation from Tikanlik weather station.

\subsection{Methods}

The geometric correction and pixel resampling were applied to the remote sensing images of 2009 (The topographic map of 1:100,000 was used as reference). Then the remote sensing images in 1990 and 2000 were compared with the corrected images of 2009. These works were carried out using ArcGIS software. The vector and attribute data of landscape types in different periods were obtained by reading remote sensing interpretation keys (read alternately by human and computer), which were established based on the image tone and texture of different land-cover types in the GIS environment.

At present there is not an internationally accepted land use classification system in use (Zhou et al., 2010). Hence, LCCS (Land Cover Classification System) was employed in the present paper. Two levels of land classification were prepared in the study, with the first level including farmland, woodland, grassland, water bodies, residential and industrial land and unused land. The second (more detailed) level comprises (1) woodland (made up of forest land, shrub land, sparse woodland and others), (2) grassland (divided into three cover types-high, middle and low), (3) riparian zone (river, channel, lake, reservoir, beach and marshland), (4) residential and industrial land including urban and rural residential land and construction land. Desert, gobi, saline or alkaline land and bare land are classified into undeveloped land. Linear objects such as highways, country roads, some canals and shelterbelts have not been given a classification. The final classification map is shown in Fig. 2.
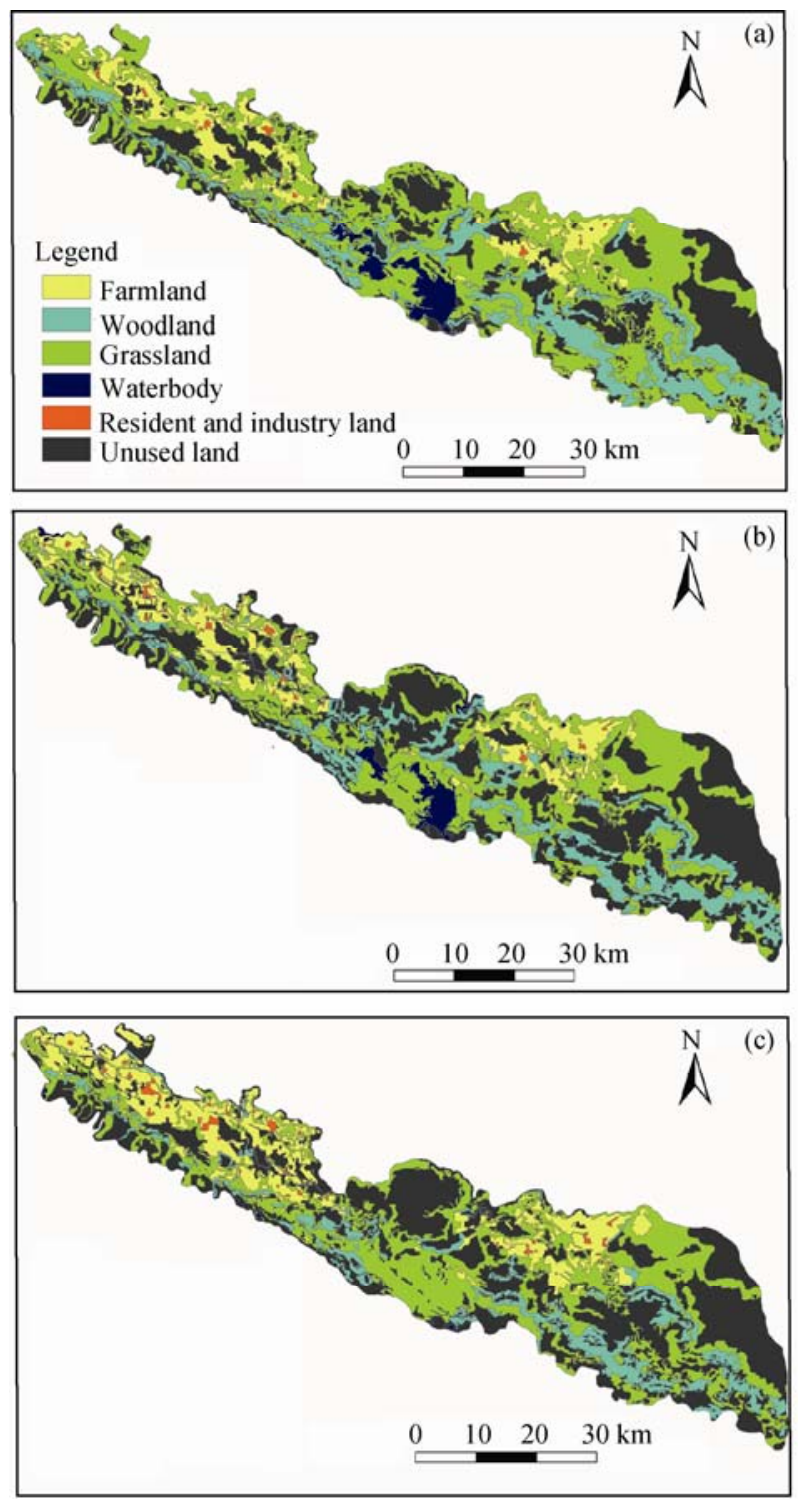

Fig. 2 Maps of oasis land use in the development area of the lower reaches of the Tarim River, (a) 1990; (b) 2000; (c) 2009

In order to evaluate the reliability of the classification results, precision inspection was carried out to the classification results of 2009 by using random sampling. One hundred and fifty sample points were randomly selected from the classification map of 2009, and reviewed on the ground during the middle ten days of August 2010. We found that the interpreted accuracy of all land use types was all above $80 \%$. This 
indicated that further analysis of the changes in the landscape pattern and oasis stability in present study was feasible.

\subsection{Analysis of oasis stability}

The variation in oasis area is absolute, but the stability of oasis is relative, and as referred to in the introduction, oasis stability is different at different spatio-temporal scales. The optimal method for valuing oasis stability is the evaluation index system, however, qualitative analysis is a precondition for quantitative analysis. Without qualitative analysis, quantitative analysis is blindfolded. In addition, most people's understanding of the structure, function and dynamic changes in oases is still at the qualitative level. The analysis adopted in the paper is also qualitative analysis. Oasis stability according to landscape scale was analyzed from the variation in landscape pattern and land use degree, and the oasis stability at the regional scale was valued from aspects of the indexes of 'cold-island effect' and vegetation.

\section{Results}

\subsection{The oasis stability at the landscape scale}

4.1.1 Influences of the landscape pattern to the oasis stability

The more types of landscape patches and the smaller the size of these patches, the stronger is the landscape heterogeneity, and the greater will be the instability of the oasis landscape, and vice versa (Luo et al., 2002). Landscape pattern is not only the embodiment of landscape heterogeneity; it is also the product of the interactions between each and every ecological process (Wu, 2000; Fu et al., 2001).

The quantitative index system (reflecting the structure and the spatial distribution of the landscape pattern) can highly condense the information on the landscape pattern (Wang et al., 2006). Using landscape pattern index to analyse the structure and the space configuration within the landscape, and then to explain the function of the landscape is a commonly used method. The vector data for each of the three years of imagery were transformed onto $50 \mathrm{~m} \times 50 \mathrm{~m}$ grids using the conservation tools in ArcGIS, and from these the index of the landscape patterns were calculated. The changes in the landscape pattern with time were analyzed from the change of the structure and the spatial heterogeneity of the landscape. The selection of a suitable landscape index was decided according to the aims of the investigation, the scale analyzed and the meaning the index expressed. The index of the landscape spatial pattern of the oasis in the lower reaches of the Tarim River was calculated from the formula of the quantitative index (Table 1), (which was selected to analyze the landscape pattern). Subsequently, the index of the landscape spatial pattern was employed to further assess the oasis stability.

From Table 2 we can see that the changes of the landscape indices in the study area are conspicuous. From 1990 to 2000, the indices for diversity and the evenness were growing, revealing that (1) the differences between the proportion of each landscape type were decreasing, (2) the degree of the landscape heterogeneity and the complexity of the landscape structure were improving, and (3) the stability of oasis was decreasing. The dominance index reduced from 0.4151 (in 1990) to 0.4030 (in 2000), indicating that the proportion of the dominant landscape type was decreased, and the dominating effect of the dominant landscape type on the whole landscape was reduced and weakened.

Both $\mathrm{H}$ (diversity index) and $\mathrm{E}$ (evenness index) decreased from 2000 to 2009, while the dominance index increased. These indicate that the heterogeneity and the complexity of the landscape shrank, and the oasis stability was enhanced. The indices of the landscape fragmentation for all three observations are all low, showing that the degree of landscape fragmentation is low and that the landscape is integrated as a whole.

4.1.2 Influences of land use change to the oasis stability

The change in land cover in the oasis is the result of vast negative entropy input by humans. In general, higher input of negative entropy means a higher degree of land use in an oasis. This is beneficial for the transformation of oases from instability to stability, and achieving the sustainable development of oases. In the paper, the comprehensive index of the degree of the oasis land use in the lower reaches of the Tarim River was calculated using the method of Liu (1992), in which the comprehensive index model of degree of land use was proposed.

Table 3 showed that from 1990 to 2000 the comprehensive index of land use reduced from $45.73 \%$ to $43.57 \%$ ( $-2.17 \%$ change, $-4.74 \%$ rate of change). 
Table 1 The diagnostic indices and ecological meaning of the spatial pattern of the landscape

\begin{tabular}{|c|c|c|}
\hline Index & Method & Ecological meaning \\
\hline $\begin{array}{l}\text { Total area of the landscape (A) and } \\
\text { the quantity of the patch (M) }\end{array}$ & Statistic from GIS & Basic of landscape pattern analysis \\
\hline Landscape diversity index $(\mathrm{H})$ & $\begin{array}{l}H=-\sum_{i=1}^{m} p_{i} \times \ln p_{i} \text {, where } p_{i} \text { is landscape area proportion of } \\
\text { patch } i ; m \text { is number of patch types }\end{array}$ & Measurement of landscape complexity and variability \\
\hline Landscape dominance index (D) & $D=H_{\max }+\sum_{i=1}^{m} p_{i} \times \ln \left(p_{i}\right)$ & $\begin{array}{l}\text { Test for degree of deviation in landscape diversity from } \\
\text { maximum diversity, or description of the degree of } \\
\text { dominance to the landscape pattern of one or several } \\
\text { embedded landscape blocks }\end{array}$ \\
\hline Landscape evenness index (E) & $E=H / H_{\max }=-H / \ln (1 / m)$ & $\begin{array}{l}\text { Reflection of the degree of dominance of a few major } \\
\text { landscape types in the landscape }\end{array}$ \\
\hline landscape fragmentation index $(\mathrm{C})$ & $\begin{array}{l}C=\sum N_{j} / \sum A i \text {, where } \sum N_{j} \text { are total numbers of landscape } \\
\text { patch; } \sum A_{i} \text { is total area of landscape }\end{array}$ & $\begin{array}{l}\text { Used to describe the degree of the landscape fragmenta- } \\
\text { tion and the complexity of the landscape structure }\end{array}$ \\
\hline
\end{tabular}

Table 2 The index of the landscape spatial pattern of the oasis in the lower reaches of the Tarim River from 1990 to 2009

\begin{tabular}{cccccc}
\hline Year & $\begin{array}{c}\text { Landscape area } \\
(\mathrm{A})\left(\mathrm{hm}^{2}\right)\end{array}$ & $\begin{array}{c}\text { Patch numbers } \\
(\mathrm{M})\end{array}$ & $\begin{array}{c}\text { Landscape diversity } \\
\text { index (H) }\end{array}$ & $\begin{array}{c}\text { Landscape dominance } \\
\text { index (D) }\end{array}$ & $\begin{array}{c}\text { Landscape evenness } \\
\text { index (E) }\end{array}$ \\
\hline 1990 & 268229.72 & 591 & 1.3766 & 0.4151 & 0.7683 \\
2000 & 268229.73 & 731 & 1.3887 & 0.4030 & 0.0022 \\
2009 & 268229.73 & 565 & 1.3371 & 0.4546 & 0.0021 \\
\hline
\end{tabular}

Table 3 The comprehensive indices and the change in the degree of land use for the oasis in the lower reaches of the Tarim River

\begin{tabular}{|c|c|c|c|c|c|c|c|c|c|c|c|c|}
\hline \multirow{4}{*}{$\begin{array}{c}\text { Oasis in the } \\
\text { lower reaches } \\
\text { of the Tarim } \\
\text { River }\end{array}$} & \multirow{2}{*}{1990} & \multirow{2}{*}{2000} & \multirow{2}{*}{2009} & \multicolumn{2}{|c|}{2000 vs 1990} & \multirow{2}{*}{$\begin{array}{c}1990-2000 \\
\text { Average } \\
\text { variable quantity }\end{array}$} & \multicolumn{2}{|c|}{2009 to 2000} & \multirow{2}{*}{$\begin{array}{c}2000-2009 \\
\text { Average } \\
\text { variable quantity }\end{array}$} & \multicolumn{2}{|c|}{2009 vs 1990} & \multirow{2}{*}{$\begin{array}{c}\text { 1990-2009 } \\
\text { Average } \\
\text { variable quantity }\end{array}$} \\
\hline & & & & $\begin{array}{l}\text { Variable } \\
\text { quantity }\end{array}$ & $\begin{array}{c}\text { Change } \\
\text { rate }\end{array}$ & & $\begin{array}{l}\text { Variable } \\
\text { quantity }\end{array}$ & $\begin{array}{c}\text { Change } \\
\text { rate }\end{array}$ & & $\begin{array}{l}\text { Variable } \\
\text { quantity }\end{array}$ & $\begin{array}{c}\text { Change } \\
\text { rate }\end{array}$ & \\
\hline & \multicolumn{12}{|c|}{$(\%)$} \\
\hline & 45.73 & 43.57 & 43.81 & -2.17 & -4.74 & -21.68 & 0.25 & 0.56 & 2.450 & -1.92 & -4.20 & -19.23 \\
\hline
\end{tabular}

This indicates that the oasis stability decreased. From 2000 to 2009 the comprehensive index of land use increased from $43.57 \%$ to $43.81 \%$ ( $0.25 \%$ change, $0.56 \%$ rate of change). The degree of land use improved and the oasis stability was enhanced. From the view of the whole period (1990 to 2009), the change value of the land use is $-1.92 \%$ and the change rate is $-4.2 \%$. These values are lower than those of the earlier period and higher than those in the later period, indicating that the oasis stability in the later period has improved. However, the comprehensive stability of the oasis from 1990 to 2009 is reduced.

\subsection{The oasis stability at the regional scale}

4.2.1 The cold-island effect and the stability of the oasis

The analysis of the oasis stability at a landscape scale only considered the inner structure of the oasis. It is necessary to present an analysis by treating the oasis, desert and mountain as a whole (Luo et al., 2003), in other words, the interaction between oasis and outer desert and mountain systems should be studied. The cold-island effect was employed to measure these interactions.

The special climate characters and the surface properties of desert and oasis result in the thermal heterogeneity of the underlying surfaces in arid areas, and result in the colder state of the oasis than the surrounding desert (Su et al., 1987). This phenomenon is known as the cold-island effect. The formation process of the cold-island effect was explained in detail by Luo (2003).

The research of Lv et al. (1995), which studied the influences of the underlying surface state of oases and desert to the atmospheric boundary layer features by using the technology of two dimensional high resolution boundary layer numerical simulation, revealed that: (1) the cold-humid effect produced by oases contribute to the formation of cold-humid gaseous columns in the sky above oases and (2) the hot-dry effect brought about by deserts promote the formation of hot-dry airflow in the sky above the desert, which is favorable to precipitation at the edge of oases. 
The formula of the cold-island effect can be expressed as follows:

$$
S_{i}=\frac{P_{i}}{\bar{P}} \times \frac{W_{i}}{\bar{W}} \times \frac{\bar{V}}{V_{i}} .
$$

Where, $S_{i}$ is the index of the cold-island effect in the year i; $P_{i}, W_{i}$ and $V_{i}$ are the amount of of precipitation $(\mathrm{mm})$, river runoff $\left(\mathrm{m}^{3}\right)$ and evaporation $(\mathrm{mm})$, respectively; $\bar{P}, \bar{W}$ and $\bar{V}$ are annual average precipitation, amounts of river runoff and evaporation, respectively. The cold-island effect is enhanced only when $\sum \mathrm{S}_{\mathrm{i}} / \mathrm{n} \geqq 1$ (n represents the number of years between
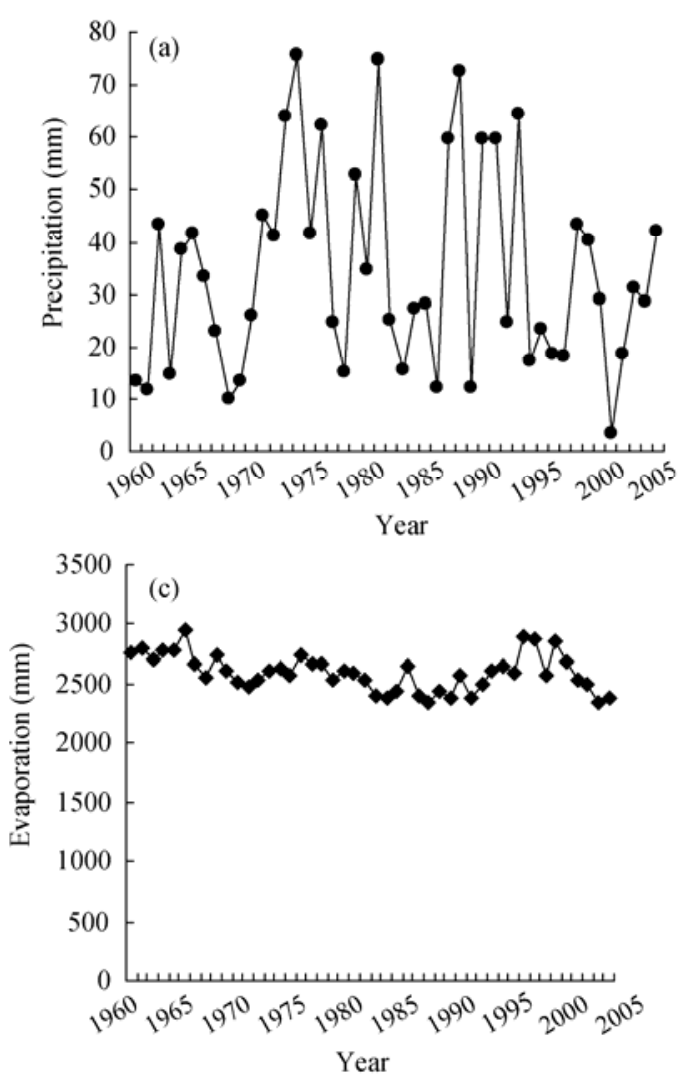

starting and ending years selected for research).

On the basis of the data of runoff from Qiala station and the precipitation and ground evaporation from Tikanlik station (Fig. 3), the index of the cold-island effect from 1960 to 2005 in the lower reaches of the Tarim River was calculated in terms of Eq. 1 (Table 4).

Table 4 shows that the average index of the cold-island effect during the whole studied period (1960 to 2005) is 0.946 . The average index from 1960 to 1990 is 1.164 , higher than the average for the whole studied period, and greater than 1 , indicating that the
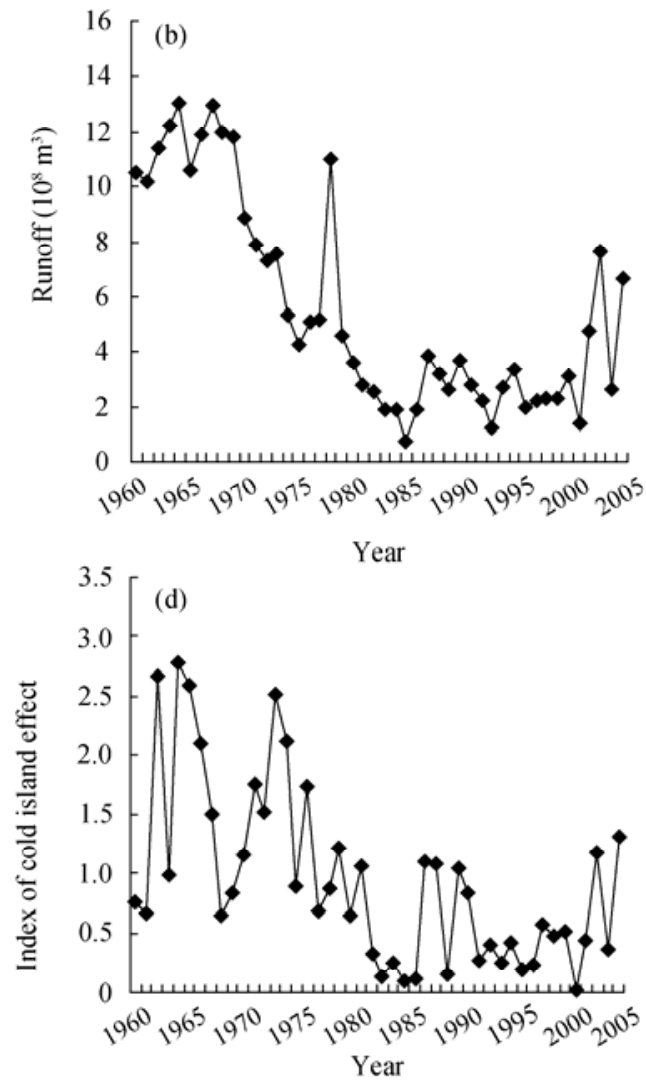

Fig. 3 The curve of the indices of the precipitation (a), evaporation (c), runoff (b) and cold island effect (d) of the oasis in the lower reaches of the Tarim River from 1900 to 2005

Table 4 The index of the cold-island effect of the oasis in the lower reaches of the Tarim River from 1990 to 2005

\begin{tabular}{ccccccccccccc}
\hline Year & 1960 & 1961 & 1962 & 1963 & 1964 & 1965 & 1966 & 1967 & 1968 & 1969 & 1970 & 1971 \\
\hline Index & 0.770 & 0.670 & 2.667 & 0.986 & 2.770 & 2.585 & 2.101 & 1.510 & 0.643 & 0.838 & 1.166 & 1.750 \\
Year & 1972 & 1973 & 1974 & 1975 & 1976 & 1977 & 1978 & 1979 & 1980 & 1981 & 1982 & 1983 \\
Index & 1.523 & 2.520 & 2.117 & 0.902 & 1.725 & 0.680 & 0.874 & 1.219 & 0.646 & 1.074 & 0.324 & 0.141 \\
Year & 1984 & 1985 & 1986 & 1987 & 1988 & 1989 & 1990 & 1991 & 1992 & 1993 & 1994 & 1995 \\
Index & 0.247 & 0.099 & 0.121 & 1.107 & 1.093 & 0.156 & 1.055 & 0.835 & 0.259 & 0.407 & 0.241 & 0.418 \\
Year & 1996 & 1997 & 1998 & 1999 & 2000 & 2001 & 2002 & 2003 & 2004 & 2005 & & \\
Index & 0.187 & 0.235 & 0.561 & 0.471 & 0.517 & 0.026 & 0.442 & 1.175 & 0.353 & 1.317 & & \\
\hline
\end{tabular}


cold-island effect is stronger and the oasis stability is better. The average index from 1990 to 2000 is just 0.402, lower than the average level (from 1990 to 2005), so the cold-island effect is very weak during this time, and the oasis stability is poor. The average index from 2001 to 2005 is 0.663 , a little higher than the value from 1990 to 2000 , however, it is still lower than the average level from 1960 to 2005 . So, although the oasis stability is improved in this period, it is still in a bad state.

\subsubsection{The vegetation index and the stability of the} oasis

The analysis of the cold-island effect is an investigation of the regional stability of the oasis from the view of climate. The cold-island effect is the production of the regional circulation which results from the interaction between the oasis and the desert surroundings. This interaction is produced by the physical differences between the desert and the underlying surface of the oasis (Chen, 2008). The main factor influencing this physical difference in arid areas is the vegetation.

The differences of the underlying surface in arid regions are closely related to the variation in the distribution density of the vegetation. In terms of the connotation of the oasis stability at the regional scale (Luo et al., 2004), the oasis stability and the vegetation density are closely related to plant biomass. The relationship between vegetation density and vegetation biomass is positively correlated, and the oasis stability is proportional to the biomass. So, it is necessary to analyze the stability of the oasis from the view of vegetation variation.

NDVI (Normalized Difference Vegetation Index) indicates the growing state of plants and their density on the ground surface. NDVI is positively correlated to the plant distribution density and is widely used (Zhang et al., 2008). This vegetation index is an important parameter for estimating biomass. Although it is not the direct measurement of primary productivity, the density of vegetation cover, measured by NDVI, is closely related to plant biomass. The positive correla- tion and the linear relationship (or nonlinear relationship) between the vegetation index and vegetation coverage and the biomass have been established (Chong et al., 1993; Prince et al., 1995), who have shown that the degree of the coverage and the biomass of the vegetation can be reflected by the vegetation index. Thus, change in the amount of vegetation coverage and the biomass of the vegetation in the oasis can be monitored by the variation in NDVI, and the oasis stability can also be judged by the variation in NDVI with time. The oasis stability is enhanced when the value of the NDVI is increased; similarly, when the NDVI is decreased the stability of the oasis is weaker. The NDVI is calculated as follows:

$$
N D V I=\left(\rho_{\text {nir }}-\rho_{\text {red }}\right) /\left(\rho_{\text {nir }}+\rho_{\text {red }}\right) \text {. }
$$

Where, $\rho_{\text {nir }}$ and $\rho_{\text {red }}$ are the reflectivity of near infrared and red waves, respectively.

Geometry and radiation correction under ENVI 4.5 were conducted on the three TM images, and the NDVI indices for the 1990, 2000 and 2009 imagery were extracted to build grey images, and mathematical statistics of the NDVI indices for each image (Table 5).

Table 5 shows that the change of the average index of the oasis vegetation is obvious. The NDVI is -0.0062 in 1990 , and reduced to -0.0197 in 2000 , indicating that from 1990 to 2000 the vegetation coverage and the oasis stability had decreased; from 2000 to 2009 , the NDVI value increased, revealing the increase in the vegetation coverage and the oasis stability. After comparing the NDVI of 1990 with 2009, we found that the former is lower than the latter, this indicates that the coverage of the vegetation in 1990 is smaller than that in 2009. However, this phenomenon is not consistent with the factual situation. Although the natural vegetation in the Tarim River basin has recovered to some extent since the implementation of comprehensive treatment, the level of vegetation coverage is far lower than it was in the 1990s. This may result from the different imaging times (October in 1990 and August in 2000 and 2009).

Table 5 The NDVI index of the oasis in the lower reaches of the Tarim River in different periods

\begin{tabular}{ccccc}
\hline Year & Minimum & Maximum & Average & Standard deviation \\
\hline 1990 & -0.4706 & 0.5360 & -0.0062 & 0.0467 \\
2000 & -0.5294 & 0.6071 & -0.0197 & 0.0911 \\
2009 & -0.3469 & 0.6364 & 0.0088 & 0.0818 \\
\hline
\end{tabular}




\section{Disscussion and conclusions}

Oasis stability is an important aspect for the study of oases and arid regions. The comprehensive results revealed that:

(1) At the landscape scale, the stability of the oasis characterized by the index of the landscape pattern and the index of degree of land use reduced from 1990 to 2000, and increased from 2000 to 2009;

(2) At the regional scale, the variation of the oasis stability characterized by the change of index of the cold-island effect and the NDVI is consistent with the change trend at the landscape scale;

(3) By considering all the indices synthetically we found that: from 2000 to 2009, although the oasis stability was enhanced to some extent, it has been reduced over the period of the whole study (1990 to 2009). The oasis stability is still weak in this period.

From the conclusions above we can see that the changing trends of the oasis stability in the lower reaches of the Tarim River, characterized by different indices, are consistent. In other words, the indices used in this study are all suitable for characterizing the oasis stability in the lower reaches of the Tarim River.

In order to increase the oasis stability in the lower reaches of the Tarim River, some measures are worthy of consideration: (1) to reasonably enlarge the size of the oasis to enhance the cold-island effect, as Luo et al. (2003) described. The expansion of the oasis and augmenting the water supplies and the vegetation within the oasis should contribute to the enhancement of the cold-island effect, and result in the increased precipitation and reduced evaporation, this boosting the stability of the oasis, and (2) to increase the coverage of the natural vegetation.

The implementation of the above schemes is closely related to the water resources in this region. However, the precipitation in the Tarim River Basin is extremely scanty, and in some years it is non-existent. In recent years the runoff of the Tarim River has decreased sharply, especially in the lower reaches region, due to the increasing population, excessive water use for irrigation, and random land clearing. So, in order to increase the oasis stability in the downstream region of the Tarim River the urgent matter is to improve the water resources in this region. Here, one thing worthy to be pointed out is that the implementation of the ecological water conveyance engineering in the lower reaches of the Tarim River since 2000 produced key positive effects on oasis stability. It is very beneficial for the sustainable development of oases in this region to continue the implementation of the ecological water conveying engineering.

The present paper investigated the oasis stability and its variation with time at both landscape and regional scales. Further work is needed in future to more fully elucidate the factors that drive oasis stability.

\section{Acknowledgements}

This research was supported by the National Basic Research Program of China (2010CB951003), National Natural Science Foundation of China (40901061), Key Topics in Innovation Engineering of the Chinese Academy of Sciences (KZCX2-YW-Q10-3-4) and Western Talent Cultivation Plan (XBBS200907). The authors are grateful to the staff of the Key Laboratory of Oasis Ecology and Desert Environment, Xinjiang Institute of Ecology and Geography, who gave help to review the sample points in the field, and also thank teacher WeiHong LI for the method instruction.

\section{References}

Chen X. 2008. Land Use/Cover Change in Arid Areas in China. Beijng: Science Press, 490-498.

Chen Y N, Li W H, Xu H L, et al. 2003. The influence of groundwater on vegetation in the lower reaches of Tarim River, China. Acta Geographica Science, 58(4): 542-549.

Chen Y N. 2010. Study on the Eco-hydrological Problem in Tarim River Basin, Xinjiang. Beijing: Science Press, 170-173.

Chong D L S, Mougin E, Gastellu-etchegerry J P. 1993. Relating the global vegetation index to net primary productivity and actual evapotranspiration over Africa. International Journal of Remote Sensing, 14(8): 1517-1546.

Fu B J, Chen L D, Ma K M, et al. 2001. The Theory and Application of Landscape Ecology. Beijing: Technology Press, 57-60.

Han D L, Meng X Y. 1999. Recent progress of research on oasis in China, Chinese Geographical Science, 9(3): 199-205.

Jiao Y M, Ma M G, Xiao D N. 2003. Research on the landscape pattern of Zhangye Oasis in the middle reaches of Heihe River. Journal of Glaciology And Geocryology, 25(1): 94-99.

Liu H, Zhong H P, Gu Y. 2001. Water resources development and oasis evolution in inland river basin of arid zone of northwest China-a case study: Minqin Basin of Shiyang River. Advances in Water Science, 12 (3): 378-384.

Liu J Y. 1992. Land Use in Tibet. Beijing: Science Press, 78-96.

Luo G P, Chen X, Zhou K F, et al. 2002. Study of spatiotemporal variation and stability of oasis in Sangong River Basin. Science in China, Series D, 32(6): 521-528.

Luo G P, Zhou C H, Chen X. 2003. Process of land use/land cover change in the oasis of arid region. Acta Geographica Sinica, 58(1): 63-72.

Luo G P, Zhou C H, Chen X, et al. 2004. Evaluation of the stability of the 
oasis at the regional scale. Journal of Science Resources, 19 (4): 519-524.

Lv S H, Chen Y C. 1995. Numerical simulation of the influence of oasis and desert on atmospheric boundary layer. Journal of Desert Research, 15 (2): 116-123.

Ma M G, Wang X M, Jiao Y M. 2003. Study on the change of landscape pattern of oasis in arid region based on RS and GIS methods - application of Jinta Oasis. Journal of Desert Research, 23 (1): 53-58.

Prince S D, Goward S N. 1995. Global primary production: a remote sensing approach. Journal of Biogeography, 22: 815-835.

Song D M, Xiao D N, Zhang Z C, et al. 2003. Landscape changes of Minqin oasis in Gansu Province and its driving force. 1Chinese Journal of Applied Ecology, 14 ((4): 535-539.

$\mathrm{Su} \mathrm{C} \mathrm{X}, \mathrm{Hu}$ Y J. 1987. Cold island effect of oasis and lake. Chinese Science Bulletin, 31 (10): 756-758.

Wang X Z, Zheng Y H, Li S. 2006. Analysis of land use and landscape pattern change in west of Hainan Island. Journal of Desert Research, 26 (3): 409-414.

Wang Y X, Zhang X L, Kan Y P. 1999. Study on oasis regional system and the spatial envelopment. Arid Land Geography, 22 (1): 62-68.
Wang Z J, Wang H F, Lei Z D. 2002. Stability analysis of oasis in arid region. Journal of Hydraulic Engineering, (5): 26-30.

Wu J G. 2000. Landscape Ecology_Pattern, Process, Scale and Grade. Beijing: Higher Education Publishing Company, 30-64.

Wu X X, Zou X Y, Ge R L, et al. 2009. Research on landscape pattern of Uxin Qi in Inner Mongolia based on "3S" technology. Journal of Desert Research, 29 (5): 808-814.

Zhang K, Si J H, Wang R Y, et al. 2008. Impact of climate change on desert vegetation in Alxa region. Journal of Desert Research, 28 (5): $879-885$.

Zhao W Z, Chang X L, He Z B, et al. 2006. Study on ecological water requirements of vegetation in Ejina desert oasis. Science in China, Series D, 36 (6): 559-566.

Zhou D C, Luo G P, Lu L. 2010. Processes and trends of the land use change in Aksu watershed in the central Asia from 1960 to 2008. Journal of Arid Land, 3(2): 157-166.

Zhou H R, Xiao D N. 2010. Ecological function regionalization of fluvial corridor landscapes and measures for ecological regeneration in the middle and lower reaches of the Tarim River, Xinjiang of China. Journal of Arid Land, 2(2): 123-132.

\section{Felidae (Wild Cats) in Xinjiang was published}

A book, Felidae (Wild Cats) in Xinjiang was published by LAP Lambert Academic Publishing (Germany) recently, and was mainly edited by Prof. Ablimit Adbukadir from Xinjiang Institute of Ecology and Geography, Chinese Academy of Sciences.

The book systematically reports the morphological and biological characteristics, the eco-logical biology, natural and unnatural factors of its habitat, population resources status, utilizing and protection of wild cats in Xinjiang based on the support of National Natural Science Foundation of China and other projects nearly 20 years.

The book is basically divided into two parts, the first part briefly describes five kinds of cat animals including the existing cats (Asian wild cat and Felis silvestris), Chinese desert cats (China lynx and desert cat), steppe cat, lynx (Eurasian lynx) and snow leopard in Xinjiang. The second part systematically describe the characteristics of heterogeneity distribution of wild cats, the carnivorous species, the living status and the population dynamics of wild cats, the extinct Xinjiang tiger and the protection measures of other cats in Xinjiang.

The book provides a good reference for scientists, teachers, students and managers, who are engaged in research on wild zoology, wildlife ecology, wildlife and conservation biology, carnivores ecology and animal protection and management. 